\title{
THE EFFECT OF ROLL WAVES ON THE HYDRODYNAMICS OF FALLING FILMS OBSERVED IN VERTICAL COLUMN ABSORBERS
}

\author{
William A. Miller, Ph.D., Research Engineer \\ Oak Ridge National Laboratory \\ Buildings Technology Center, Energy Division \\ 1 Bethel Valley Road, Bldg. 3147, MS 6070 \\ Oak Ridge, TN 37831-6070, USA \\ Majid Keyhani, Ph.D., Professor \\ University of Tennessee-Knoxville \\ Mechanical and Aerospace Engineering and Engineering Science Department \\ Knoxville, TN 37996-2210, USA
}

\section{ABSTRACT}

A thin falling film is well suited to simultaneous heat and mass transfer because of the small thermal resistance through the film and because of the large contact surface achievable at low flow rates. The film enters as a smooth laminar flow and quickly transitions into small-amplitude wavy flow. The waves grow in length and amplitude and are identified as roll waves. This flow regime is termed "wavylaminar flow," and modern heat and mass transfer equipment operate in this complicated transition regime. Research published in open literature has shown the mass flow rate in the roll waves to be about 10 to 20 times greater than that in the laminar substrate. As the film fully develops, the waves grow in mass and the film substrate thins because fluid is swept from the substrate by the secondary flows of the roll wave.

Many studies have been conducted to measure and correlate the film thickness of wavy-laminar flows. Literature data show that Nusselt's theory for smooth laminar flow can over predict the film thickness by as much as $20 \%$ for certain wavy-laminar flow conditions. The hydrodynamics of falling films were therefore studied to measure the film thickness of a free-surface falling film and to better understand the parameters that affect the variations of the film thickness.

A flow loop was set up for measuring the thickness, wave amplitude, and frequency of a film during hydrodynamic flow. Decreasing the pipe diameter caused the amplitude of the wavy flow to diminish. Measurements monitored from stations along the falling film showed a thinning of film thickness. Fully developed flow required large starting lengths of about $0.5 \mathrm{~m}$. The film thickness increases as the Reynolds number ( $\mathrm{Re})$ increases. Increasing the Kapitza number (Ka) causes a decrease in the film thickness. Regression analysis showed that the Re and Ka numbers described the data trends in wavylaminar flow. Rather than correlating the Re number in discrete ranges of the Ka number as earlier researchers have done, this research made the Ka number an independent regression variable along with the Re number. The correlation explains $96 \%$ of the total variation in the data and predicts the experimental data within an absolute average deviation of $\pm 4.0 \%$. The correlation supports the calculation of a fully developed film thickness for wavy-laminar falling films.

\section{INTRODUCTION}

A great deal of research on the hydrodynamics of gas and liquid flows is available in the open literature. Falling films in the presence of vapor have been studied to determine the effect of the film's hydrodynamics on the absorption rate in the absorbers of modern day absorption chillers. However, modeling this nonlinear and transient problem is a mathematical challenge. The wall shear stress, surface tension, and body forces generate instabilities, causing the flow to transition from small capillary waves into much larger and fastermoving roll waves. The surface fluctuations and mixing induced within the roll waves are stochastic processes and modeling the flow field for a randomly changing free surface (i.e., stochastic boundary condition) remains a challenge. Brauner and Maron [1] modeled the wavy flow using an integral approach that required experimental data. Wasden and Dukler [2] solved the momentum equations using numerical techniques that required the shape of the free surface, which they derived from their experimental data. Morioka and Kiyota [3], Yang and Jou [4], Patnaik [5], and Patnaik and Perez-Blanco [6] each numerically solved the wavy-laminar flow problem for absorption of water vapor into a film of aqueous lithium bromide $(\mathrm{LiBr})$. All of these studies identified roll waves whose secondary flows within the wave significantly enhanced the transport processes beyond that of smooth laminar flow.

Interestingly, many researchers use the Nusselt film thickness in their approach for solving problems involving wavy-laminar flow. Blass [7], Wekken and Wassenaar [8], Habib and Wood [9], Morioka and Kiyota [3], Yang and Wood [10], and Miller, Perez-Blanco, and Patnaik [11] all used the Nusselt film thickness in their studies of wavy-laminar flow. In continued work, Morioka, Kiyota, and Nakao [12] used a contact needle probe to measure the minimum, maximum 
and average film thickness. Morioka, Kiyota and Nakao observed the film thickness of wavy-laminar flow to be less than the laminar film thickness of Nusselt when the Reynolds (Re) number was less than 1000; it becomes larger when the Re number exceeds 1000.

The works of Greenberg [13], Charvonia [14], Portalski [15], Allen [16], Clegg [17], and Chu and Dukler [18] all substantiate a reduction of the film thickness as the wavy-laminar falling film develops into a fully developed hydrodynamic flow.

\section{LITERATURE REVIEW OF FALLING FILM RESEARCH}

Solorio and Sen [19] showed that cylindrical falling films are unstable for all Re numbers, radius ratios and Weber numbers (We). Using stability analysis, Benjamin [20] predicted that vertical falling film flows are unstable over all flow ranges. Their results imply that all vertical falling films are naturally wavy. The kinematic viscosity, gravity, and surface tension are the dominant forces affecting falling film flows. Brauer [21], Grimley [22], Kapitza [23], and most recently, Ishigai et al. [24] described the characteristics of the flow using the independent groups of Re and Kapitza $(\mathrm{Ka})$ numbers. Ishigai and associates subdivided the falling film into five flow regimes (Table 1), which Morioka, Kiyota, and Nakao [12] depicted in the excellent still photograph of Fig. 1.

Morioka, Kiyota, and Nakao experimentally observed these differing flow regimes by using $59 \mathrm{wt} \% \mathrm{LiBr}$ flowing down a $28-\mathrm{mm}$ outside-diameter (OD) pipe (Fig. 1). They photographed the falling films at an angle of $40^{\circ}$ from the vertical axis at about 200 to $300 \mathrm{~mm}$ from the bottom of the 1.4-m-long test section. No absorption occurred during the photographing of the films. Given the regimes of Ishigai et al., the $59 \mathrm{wt} \%$ brine would have the flow fields listed in Table 1.

Table 1 Falling film flow regimes

\begin{tabular}{llc}
\hline \hline \multicolumn{1}{c}{ Flow regime } & \multicolumn{1}{c}{ Ishigai et al. definition } & Morioka et al. definition \\
\hline 1. Laminar flow & $\mathrm{Re} \leq 1.88\left(\mathrm{Ka}^{0.3}\right)$ & $\mathrm{Re} \leq 16$ \\
2. First transition & $1.88\left(\mathrm{Ka}^{0.3}\right) \leq \mathrm{Re} \leq 8.8\left(\mathrm{Ka}^{0.3}\right)$ & $16 \leq \mathrm{Re} \leq 60$ \\
3. Stable wavy-laminar & $8.8\left(\mathrm{Ka}^{0.3}\right) \leq \mathrm{Re}<300$ & $60 \leq \mathrm{Re}<300$ \\
4. Second transition & $300 \leq \mathrm{Re} \leq 1600$ & $300 \leq \mathrm{Re} \leq 1600$ \\
5. Fully turbulent & $\mathrm{Re} \geq 1600$ & \\
\hline \hline
\end{tabular}

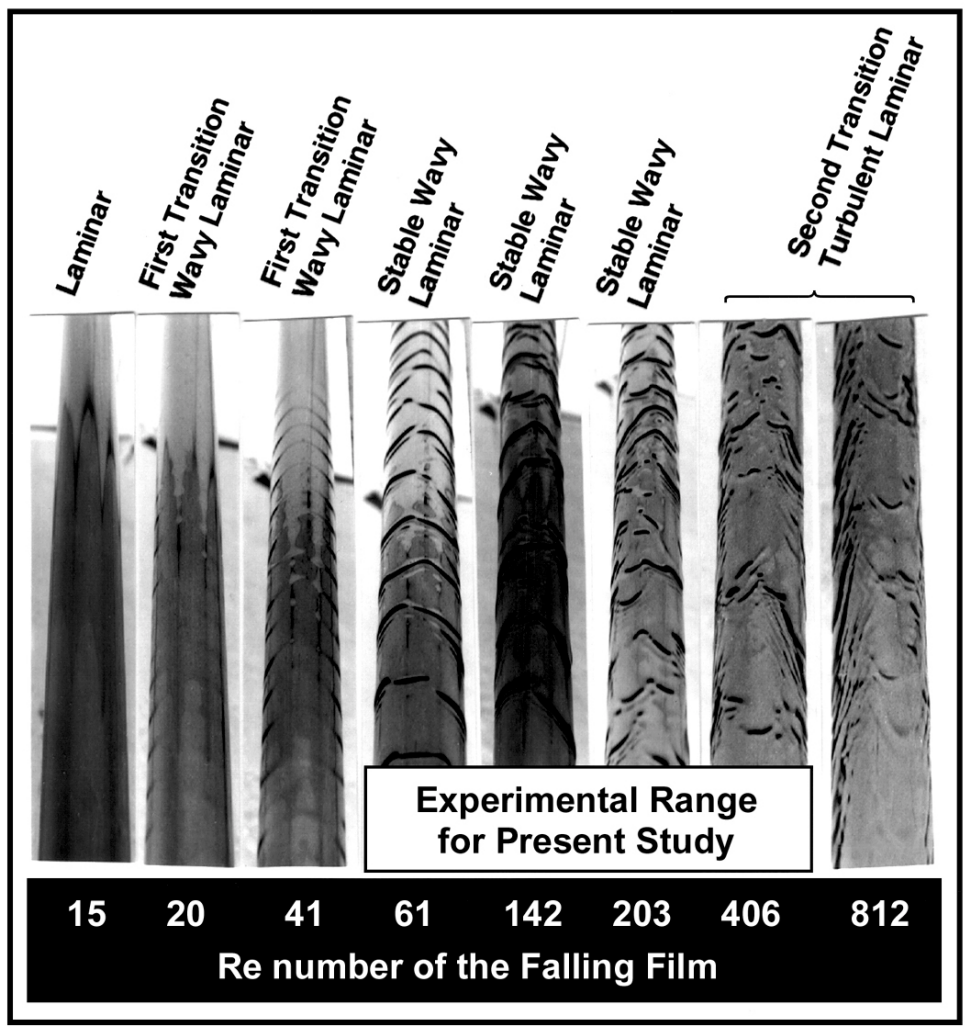

Fig. 1. Vertical falling films of $59 \mathrm{wt} \% \mathrm{LiBr}$ brine photographed on a $0.028-m-O D$ test tube (adapted from Morioka, Kiyota, and Nakao [12]). 
At a Re number of 15, Morioka, Kiyota, and Nakao observed a mirrorlike laminar flow that was completely smooth and uniform. Increasing the Re number to 20 resulted in the formation of small, uniform, symmetrical waves. Fulford [25] stated that the waves in this regime were straight and almost normal to the flow direction. Morioka, Kiyota, and Nakao noted that the flow at the inlet was smooth laminar and then began to transition into wavy flow at about $200 \mathrm{~mm}$ from the inlet. Keen observation of the first transition wavylaminar regime reveals a thin laminar sublayer that nearly covers the entire pipe (see Fig. 1, first-transition wavy-laminar). Researchers have termed this laminar sublayer the "film substrate." The film is partly laminar in the substrate and partly turbulent in the waves, and therefore the transition from laminar to turbulent flow cannot be defined by a single critical Re number. Fulford's review of the open literature through 1959 confirmed this issue. Fulford's collection of some 1013 data points by different researchers showed that the transition to turbulence in a thin film is gradual and that the reported values of the critical Re number for turbulence are scattered around about 1600 .

Brauner [26] classified the waves in the transition wavy regime as either capillary wavy-laminar or inertial wavy-laminar. In Fig. 1, the capillary waves are observed for the Re number flows of 20 and 41, and the inertial laminar waves are shown for the Re number flows of 61 and higher. The inertial laminar waves are commonly known as "roll waves" [21]. As the Re number of the falling film increases, the roll waves develop a steep front. The increase in curvature increases surface tension, and this increase, in turn, leads to the growth of smaller push waves just in front of the larger wave [25]. These push waves are clearly seen in front of the larger roll waves in the photograph of stable wavy-laminar flow in Fig. 1. Morioka, Kiyota, and Nakao observed that the roll- and push-wave combination appears to persist down the pipe. Increasing the Re number above 61 causes the wave interval to increase. The waves lose their ringlike symmetry and can be described as three-dimensional and irregular, as can be seen in Fig. 1. The flow is chaotic in the second-transition turbulent laminar regime, and the waves are starting to interfere with adjacent waves. Yet the wave substrate is still preserved. At Re numbers of 406 and 812, the waves appear distorted and chaotic. This second transition is laminar in the substrate and turbulent in the wave and is visual evidence of increased convective contributions that would enhance mass transfer for an absorption process.

In recorded film profiles Allen [16] showed that the roll-wave, push-wave pattern traveled over the film substrate. He observed this laminar sublayer to thin, and showed through an approximate calculation that the total mass traveling in the roll waves increased along the length of the pipe.

Independent studies by Clegg and Portalski [27] and Chu and Dukler [18] experimentally verified this thinning of the film substrate. Clegg and Portalski mapped the instantaneous film profile along the flow direction. A gradual reduction in the film thickness was measured upon the onset of wavy-laminar flow. Chu and Dukler calculated the mass flow in the large roll wave; surprisingly, it was 10-20 times greater than the mass flow in the substrate. Because of the deep penetration of the large roll waves into the substrate, the slowervelocity liquid in the thin substrate is continuously picked up and mixed into the wave front (Fig. 2). At a Re number of 1000, Chu and Dukler found the Re number for the substrate to be only 70 , or $7 \%$ of

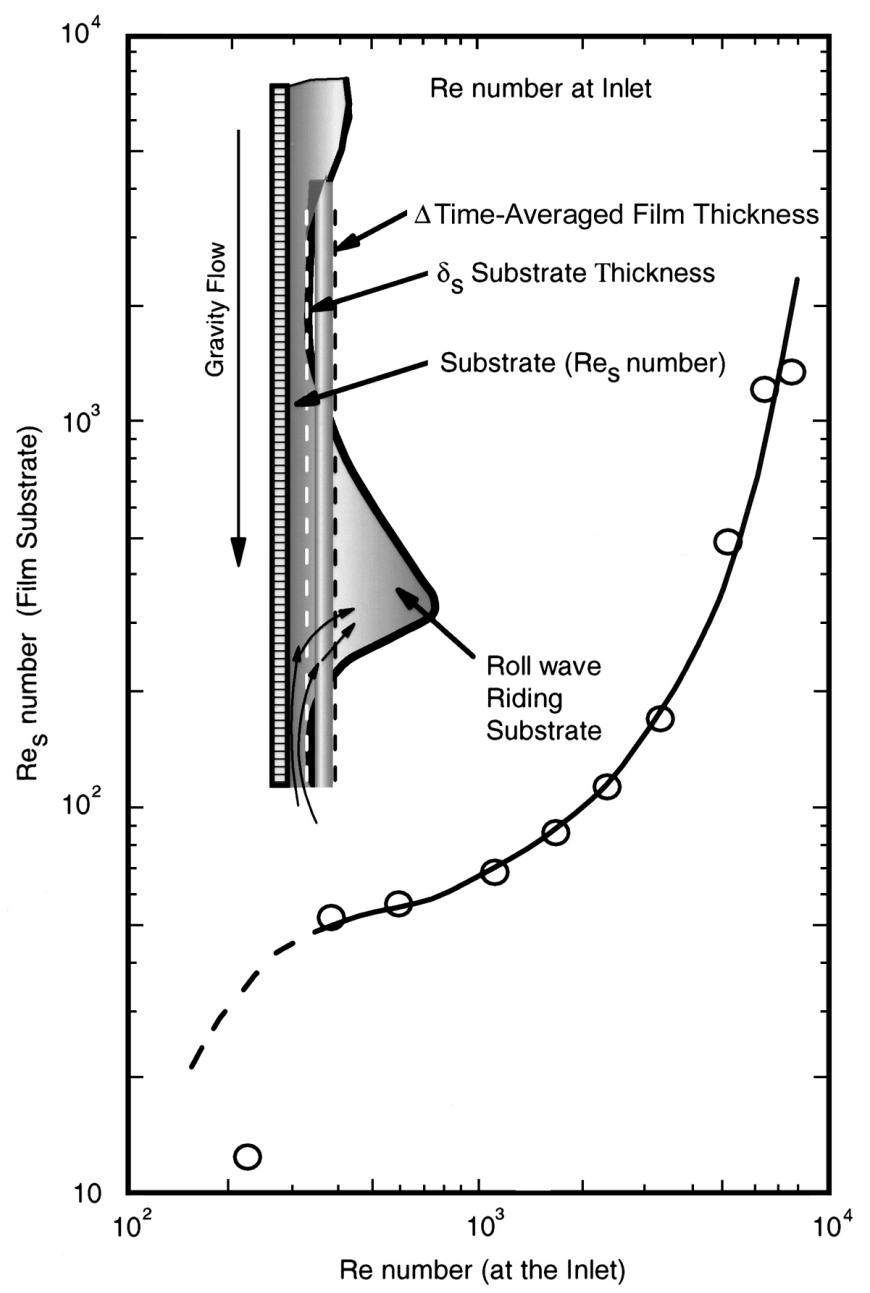

Fig. 2. Reynolds (Re) number of the flow in the substrate of a falling film compared with the Re number of the total liquid flow (adapted from Chu and Dukler [18]).

the total flow (Fig. 2). Hence, both studies implied that the film was accelerating down the pipe as the falling film transitioned into fully developed flow.

Greenberg [13] measured the film thickness at several stations located $165,292,422,540$, and $670 \mathrm{~mm}$ along the running length of a falling film. Allen [16] did similar work, measuring the film at 127, 305,457 , and $610 \mathrm{~mm}$ below the film's inlet. The large starting lengths required for the flow to become fully developed surprised them. Using the thickness $(\Delta)$ as the characteristic dimension, Greenberg determined that the length for fully developed flow was between 960 and $1380 \Delta$. Morioka, Kiyota, and Nakao [12] observed that the thickness of the waves increased down the pipe as the falling film flow fully developed. Similarly, Ishigai et al. [24] observed that the wave crests for water grew almost linearly; they did not fully develop even after $2 \mathrm{~m}$. However, Ishigai and associates also observed that for $50 \%$ ethylene glycol with a Re number less than 260 , the crests reached a finite limit after about $0.5 \mathrm{~m}$.

Dukler's work proved that the major part of the falling film was carried downstream by the ever-increasing roll waves. In his 
award-winning lecture [28], he described the falling film as composed of large liquid lumps flowing over a thin substrate (Fig. 2). He hypothesized that the large wave swept up liquid from the frontrunning push waves and deposited a freshly churned film behind. Brauner and Maron [29] substantiated Dukler's concepts and proved experimentally that mass transfer occurs from within the substrate to the front of the wave in a mixing eddy. The more intense the roll waves, the greater the fluctuations in mass transfer for Re numbers increasing from 85 to 280 .

The results of Greenberg [13], Allen [16], Ishigai et al. [24], Chu and Dukler [18], and Brauner and Maron [29] have refined the hydrodynamic concepts for wavy film flow. Brauner and Maron [1] also provided excellent insight into the mechanism for the growth of the roll waves observed by Allen and $\mathrm{Chu}$ and Dukler. The experimental results depict phenomena of isolated mass-carrying waves that sweep up fluid from the slower-moving substrate (Fig. 2). The flow rate varies with time as the mass-carrying waves pass a given point. The pickup of mass is greatest at the wave's front. The waves grow in mass, accelerate down the pipe, and cause the average film thickness to thin until the flow becomes fully developed.

\section{FILM THICKNESS}

Film thickness must be carefully defined for wavy-laminar flows because the literature data can be easily misread. The thickest and thinnest portions of the film represent, respectively, the wave crest and the film substrate (see $\delta_{\mathrm{s}}$ in Fig. 2). The reported average, however, is best represented by a time-averaged film thickness because the roll waves cause the mass flow rate of the film to vary with time. Highspeed video recordings and capacitance and photometric techniques can detect small changes in the film thickness over timed intervals. Several waves pass a detection point over time, and a time-averaged film thickness is calculated from the data. For pure laminar flow the time-averaged thickness is identical to that formulated by Nusselt [30]. However, for wavy-laminar flow, the time-averaged method yields an averaged film thickness that is less than that of smooth laminar flow because of wave hydrodynamics. Greenberg [13] observed that the time-averaged film thickness more accurately predicts the transfer of heat through films having large-amplitude roll waves.

Hopf [31] and Nusselt [30] were the first to develop solutions for the laminar falling-film hydrodynamics on a vertical flat plate. Their solution derived for the film thickness is

$$
\Delta=\left\{\frac{3 \dot{m} v}{\left(\pi \mathrm{D}_{\mathrm{o}}\right) \rho g}\right\}^{1 / 3}=\left\{0.75 \frac{v^{2}}{\mathrm{~g}} \mathrm{Re}\right\}^{1 / 3}
$$

Dukler [32] rearranged Eq. (1) into a normalized form and used the term $N t$ for the normalized film thickness number. Hence, Eq. (1) written in terms of $\mathrm{Nt}$ becomes

$$
\mathrm{Nt}=\frac{\Delta}{\left(\mathrm{v}^{2} / \mathrm{g}\right)^{1 / 3}}=\{0.75 \mathrm{Re}\}^{1 / 3}
$$

Fiend (as cited by Fulford [25, p. 180]) correlated data into discrete regions of the Ka number in an attempt to best predict the variation of film thickness as the falling film transitions with increasing Re number (Fig. 1). Fiend tested liquids with kinematic viscosities ranging from 1 to 20 centistokes. He did not discriminate similar flow regimes, as did Ishigai et al. (1972), and was one of the earliest to account for the effect of surface tension forces in terms of the Ka number. His empirical correlation takes the following form:

For the region $2.9 \mathrm{Ka}^{0.3}<\mathrm{Re} \leq 5.4 \mathrm{Ka}^{0.3}$

$$
\mathrm{Nt}=1.442\left(\frac{v}{v_{\mathrm{R}}}\right)^{0.025}\left[\frac{\mathrm{Re}}{4}\right]^{\left\{\frac{1}{3}\left\{\frac{v}{v_{\mathrm{R}}}\right\}^{-0.11}\right\}}
$$

For the region $5.4 \mathrm{Ka}^{0.3}<\mathrm{Re} \leq 24 \mathrm{Ka}^{0.3}$

$$
\mathrm{Nt}=1.442\left\{\frac{v}{v_{\mathrm{R}}}\right\}^{-0.005}\left[\frac{\mathrm{Re}}{4}\right]\left\{\frac{1}{3}\left\{\frac{v}{v_{\mathrm{R}}}\right\}^{-0.03}\right\}
$$

For the region $24 \mathrm{Ka}^{0.3}<\mathrm{Re} \leq 1600$

$$
\mathrm{Nt}=1.442\left\{\frac{v}{v_{\mathrm{R}}}\right\}^{-0.055}\left[\frac{\operatorname{Re}}{4}\right]\left\{\frac{1}{3}\left\{\frac{v}{v_{\mathrm{R}}}\right\}^{0.025}\right\}
$$

In these equations $v / v_{R}$ is a relative viscosity term, where $v_{R}=0.6 \times$ $10^{-6} \mathrm{~m}^{2} / \mathrm{s}$.

Kapitza and Kapitza [33] proved analytically that wavy-laminar films were thinner than the thicknesses assumed in the smooth laminar theory presented by Hopf [31] and Nusselt [30]. Their hypothesis that stable flow has the least energy potential led to a derivation based on physical arguments. They believed that a minimum film thickness corresponded to the minimum potential energy of the film and to the most stable flow. Kapitza and Kapitza's theory yielded the following solution, applicable only for wavy-laminar flows having wavelength $\lambda \geq 14 \Delta$ :

$$
\mathrm{Nt}=\{0.599 \mathrm{Re}\}^{1 / 3}
$$

Their correlation (Eq. 6) is about 7.2\% less than Nusselt's solution (Eq. 2). Kapitza and Kapitza believed that the most stable system had the least potential energy and that sinusoidal wavy flow was not necessarily the most stable flow pattern. They hypothesized that flow regimes other than sinusoidal wavy flow could lead to hydrodynamic solutions describing wavy flows with even smaller film thickness. Greenberg [13], Charvonia [14], Portalski [15], Allen [16], Clegg [17], and Chu and Dukler [18] all discovered appreciable reductions, some upwards of 20 to $25 \%$, of Nusselt's theory.

The present study was undertaken to better understand the hydrodynamic effects on the heat and mass transfer processes occurring in vertical column absorption chiller absorbers by measuring the film thickness of a falling film of $55 \mathrm{wt} \% \mathrm{LiBr}$. 


\section{FALLING FILM FLOW LOOP}

A flow loop was constructed for measuring the thickness, wave amplitude and frequency of a film during hydrodynamic flow down a test pipe $0.7 \mathrm{~m}$ long. The configuration of the loop is shown in Fig. 3. A liquid dispenser, also used in absorption experiments [34], was attached directly to the test pipe. The dispenser, consisting of a small stainless steel cup and a nozzle, can be adapted to pipes with ODs of $19.05,12.7$, or $9.53 \mathrm{~mm}$. The cup was line-bored after fabrication, and a centering collar was used to center the nozzle and provide a uniform flow of liquid between the inner wall of the nozzle and the outer wall of the test section. Beads of glass $6 \mathrm{~mm}$ in diameter were used to break up any vortex that might form as liquid flowed into the cup. Bubblein-tube levels were used to check the alignment of the test section.

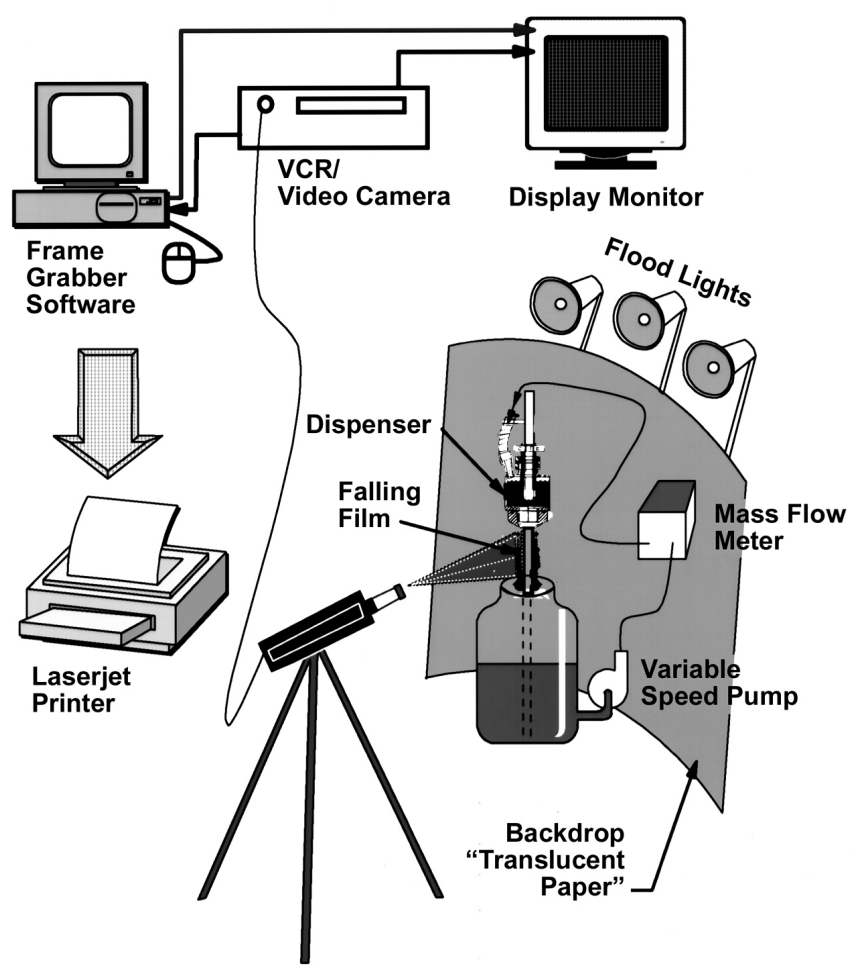

Fig. 3. Flow loop used to measure hydrodynamics of falling film.

The lower portion of the test pipe was placed into the open mouth of a 50-L carboy. A variable-speed liquid pump directed the flow of liquid from the carboy through a mass flow meter and then to the dispenser of the test section. We used a digital scale to weigh the solution entering the carboy and then timed the change in weight of the carboy to validate the accuracy of the mass flow meter. Calibrations showed the meter to be within $1 \%$ of the measurement made with the digital weighing scale.

A 35-mm camera, a VCR, and a display monitor were used to film flows of $55 \mathrm{wt} \% \mathrm{LiBr}$ brine. The falling film was viewed at different positions down the pipe to observe the development stages of the flow field. Floodlights were used to illuminate the camera's field of view; however, the nickel-plated pipe acted as a mirror and reflected the light, making it difficult to distinguish between the pipe wall and the wavy flows on the display monitor. Therefore, a thick but translucent white paper backdrop was positioned between the lighting and the test section. Opposite this backdrop, the camera viewed a darkened image of the test pipe (Fig. 3). The shadows produced by the lighting scheme better illuminated the wavy flow, and showed a more defined border of the wave for measuring the film thickness.

Data were recorded for a mass flow rate range that covered laminar to turbulent flow regimes. The flow rate was set using the variable speed pump, and the VCR was time-indexed for filming during a given flow rate. The shutter speed of the camera was 30 frames per second.

Image processing software was used to capture the recorded data frame by frame. The video signal from the VCR was monitored by the display monitor and was also digitized by an imaging software and hardware. The video could be stopped and the still image acquired by digitizing and storing it pixel by pixel. The process image was viewed on a PC monitor (Fig. 3) and also on a display monitor connected to the VCR to check for any distortion. In this manner, sequences of grabbed frames were stored in the PC's memory, and measurements of the film substrate, the wave peak, and average film thickness were calculated from the recorded images; Patnaik used imaging software to reduce the data to these film thickness measurements [5]. This approach successfully documented the hydrodynamics of the falling film, from which we quantified a fluctuating film thickness with each passing roll wave.

\section{EXPERIMENTAL RESULTS}

We made video recordings of a falling film observed on $0.7-\mathrm{m}$ long pipes with three different ODs. Film thickness was measured at different stations along the length of each pipe to observe the developing flow. Patnaik [5], in a parallel study to Miller, PerezBlanco, and Patnaik [11], reduced the data and generated approximate wave profiles over a 1.5-s time domain. The trace was taken from data for $55 \mathrm{wt} \% \mathrm{LiBr}$ with a mass flow rate of $0.022 \mathrm{~kg} / \mathrm{s}(\mathrm{Re}=270)$. Patnaik subjected the time trace to a fast Fourier transform and found a dominant wave frequency of about $13 \mathrm{~Hz}$. Similar values were derived by Brauner and Maron [29], who found a wave frequency between 14 and $16 \mathrm{~Hz}$ for a falling film Re number of 220 .

The mean film thickness, the wave peak, and the wave tail were measured on pipes having ODs of 19.05, 12.7, and $9.53 \mathrm{~mm}$. Increasing the flow rate of the falling film caused the amplitude of the waves $^{1}$ to increase on the pipe with the largest diameter (Fig. 4a). However, as seen in Fig. $4 \mathrm{~b}$ and $4 \mathrm{c}$, the wave amplitude on the smaller-diameter pipes was much less than that observed on the larger pipe. Wave inception was observed $125 \mathrm{~mm}$ down from the inlet on the $19.05-\mathrm{mm}$ pipe, whereas on the $9.53-\mathrm{mm}$ pipe, waves were not visible to the observer even after $350 \mathrm{~mm}$. Decreasing the pipe diameter decreases the mass flow rate needed for the flow to transition into the second-transition laminar-turbulent regime (Table 1). At a flow of $0.021 \mathrm{~kg} / \mathrm{s}(\mathrm{Re}=270)$, the mean film thickness was $0.48 \mathrm{~mm}$ on the $19.05-\mathrm{mm}$ pipe. But at the same flow rate, the thickness increased to $0.61 \mathrm{~mm}$ and the Re number to 540 on the $9.53-\mathrm{m}$ pipe. Fiend (as cited by Fulford [25, p. 180]) had shown that once waves appear, the film thickness dropped below the Nusselt correlation

\footnotetext{
${ }^{1}$ The wave amplitude is defined as the difference between the peak and the tail thickness.
} 


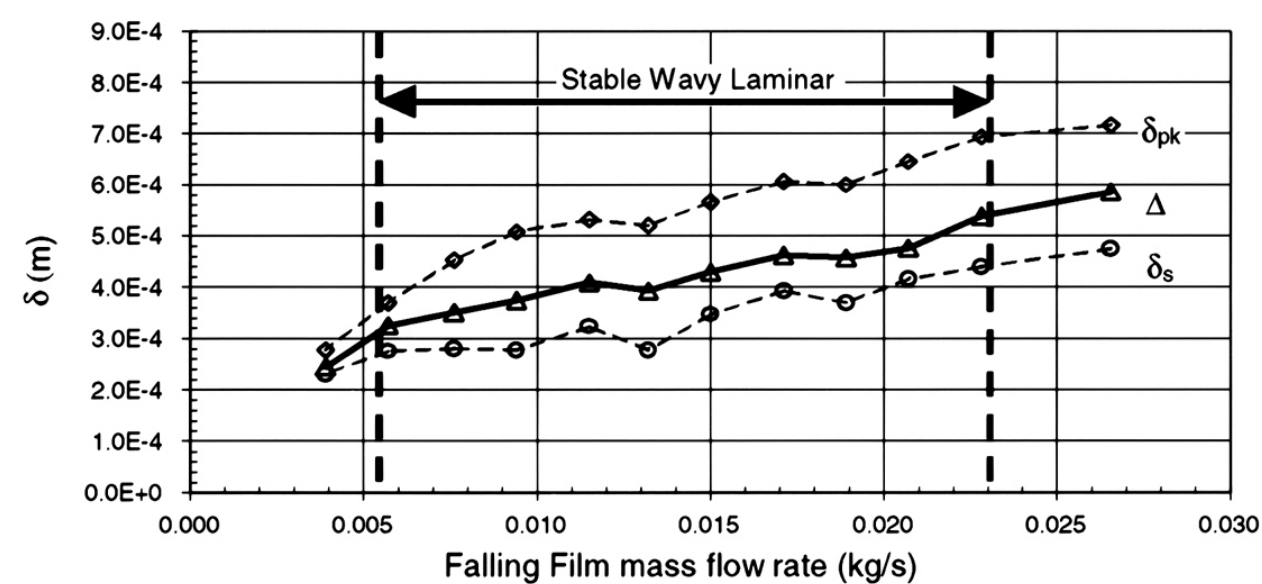

(a) Aqueous LiBr on a 0.01905-m OD tube; measurement 0.40-m down tube.

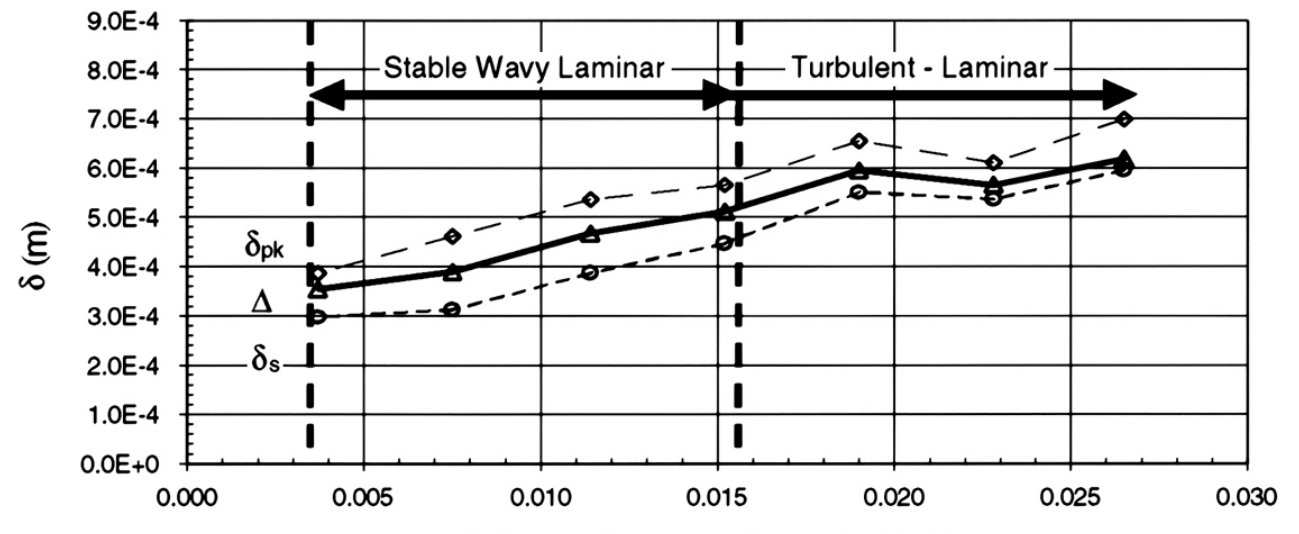

Falling Film mass flow rate $(\mathrm{kg} / \mathrm{s})$

(b) Aqueous $\mathrm{LiBr}$ on a 0.0127-m OD tube; measurement 0.33-m down tube.

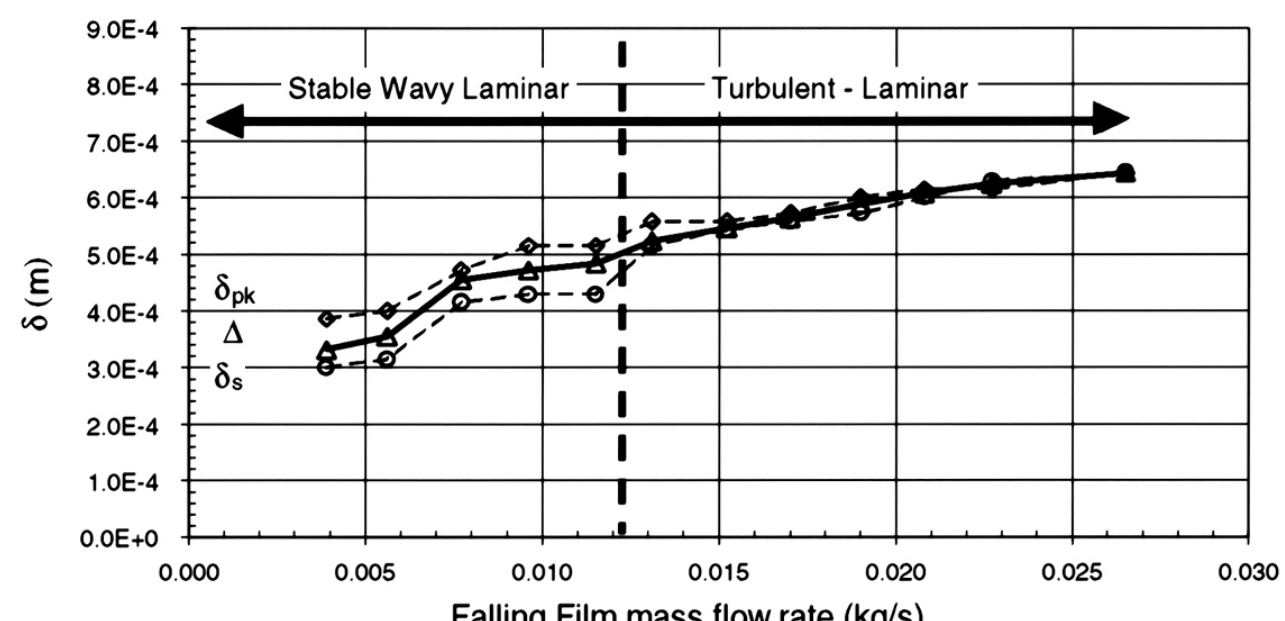

(c) Aqueous $\mathrm{LiBr}$ on a $0.009525-\mathrm{m}$ OD tube; measurement 0.35-m down tube.

Fig. 4. Peak, mean, and tail thickness of roll waves measured $0.40 \mathrm{~m}$ from the inlet for different $O D$ tubes. 
(Eq. 2), and as the Re number increased towards 1600, the thickness transitioned back and exceeded the Nusselt correlation. The observations in this study were consistent with the results of Fiend. Curvature effects may also cause the differences in wave amplitude seen in Fig. 4. The thicker film on the smaller-diameter pipe may require a greater vorticity at the liquid surface to initiate the instabilities needed for wave inception.

Throughout testing, we observed a thin film layer, which appeared to adhere to the pipe while a faster-moving roll wave traveled atop the thin layer. At the lower flow rates, if one just touched the film, it would break down and would no longer wet the entire surface. Blass [7] observed that the non-wetting patches take a cigarlike contour and usually occur below a critical Re number. We also noticed that the waves were more pronounced (larger) near the bottom of the 19.05 and 12.7-mm-OD pipes. This observation of a traveling wave reservoir that grows in the streamwise direction is consistent with the physics formulated by Allen [16], Portalski [15], Dukler [28], and Brauner and Maron [1].

Even more interesting were the trends in mean film thickness observed at three different streamwise locations for the 19.05-mm pipe (Fig. 5). Increasing the falling film flow rate increases the mean film thickness. However, as the flow exceeded $0.010 \mathrm{~kg} / \mathrm{s}(\operatorname{Re}=120)$, the mean film thickness at the measuring station $400 \mathrm{~mm}$ from the inlet deviated below that observed at either the 130 - or the $230-\mathrm{mm}$ stations located below the dispenser. For example, at $0.0194 \mathrm{~kg} / \mathrm{s}(\mathrm{Re}=290)$ the film thinned roughly $25 \%$ because of the hydrodynamics of the roll waves. Koizumi, Ohtake, and Ikeda [34] observed similar trends in their testing of R-113 flowing down a test pipe having a 25-mm OD. Their Nt film thickness reached a minimum after about $0.6-\mathrm{m}$ of free fall for a Re number flow of 400 . Once again, the results show a thinning of the film, due to fluid physics, proposed by Dukler [28] and Brauner and Maron [1].

The roll waves accelerate down the pipe as they slide over a laminar substrate. Greenberg [13] and Ishigai et al. [24] observed the falling film become fully developed after about $1000 \Delta$. As the waves accelerate down the pipe, they also grow in mass as they sweep up liquid from within the film's substrate. Therefore, the time-averaged film thickness drops below that predicted by the Nusselt formulation [30].

Clegg and Portalski [27], Chu and Dukler [18], and Allen [16] all experimentally verified this thinning. Koizumi, Ohtake, and Ikeda [34] depicted the thinning phenomena as the film fully develops down the pipe (Fig. 6). Using a video camera, they recorded the variation of the film thickness with time at several measuring stations from the inlet of a falling film of R-113. At $0.2 \mathrm{~m}$ from the inlet the time-averaged film thickness is well described by Nusselt's formulation. However, after $1.2 \mathrm{~m}$ of free fall, the substrate, which predominates on the pipe, is noticeably thinner than that predicted by Nusselt, and the timeaveraged thickness (which include waves) drops below Nusselt's correlation.

\section{CORRELATION OF THE FILM THICKNESS}

The most widely accepted technique for correlating the film thickness was developed by Dukler [32], who cast the film thickness by Nusselt [30] into the scaled format of Eq. 2. The Nt formulation was therefore selected, and the data of Greenberg [13], Charvonia [14], Portalski [15], and Allen [16], as well as our data, were reduced and plotted (Fig. 7). Greenberg, Charvonia, and Allen all used a photometric light absorption technique to measure the rapidly fluctuating film thickness of a wavy flow. Allen and Charvonia did more detailed studies on falling films of water.

Results clearly show a reduction in the measured time-averaged film thickness as compared to the Nusselt theory; the deviation is due to the presence of roll waves. For Re numbers less than 20, the data are close to laminar theory. However, the data deviate from the Nusselt curve (Eq. 2) as the wave amplitude increases, with the largest deviations observed at $\operatorname{Re}$ numbers ranging from 60 to 400 .

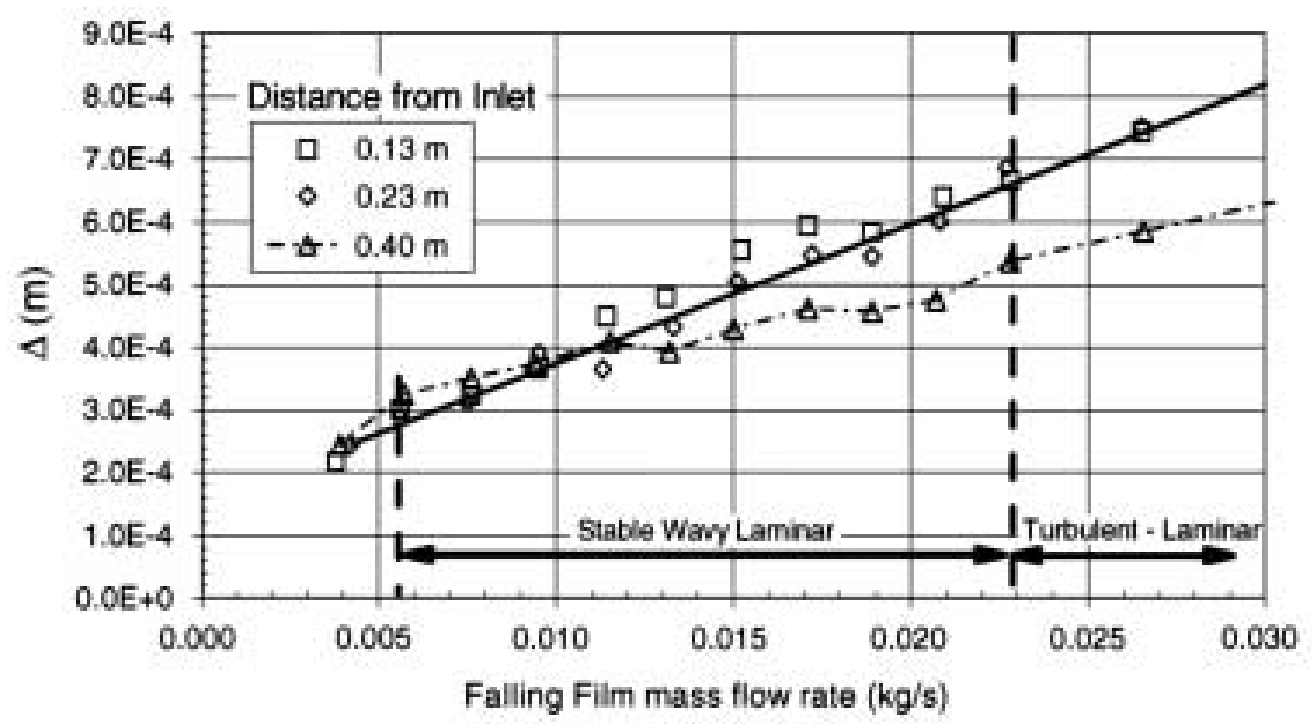

Fig. 5. Mean thickness of an aqueous $\mathrm{LiBr}$ falling film observed at three different locations on a 19.05-mm-OD pipe. The mean thickness decreases as the film fully develops in the streamwise direction. 

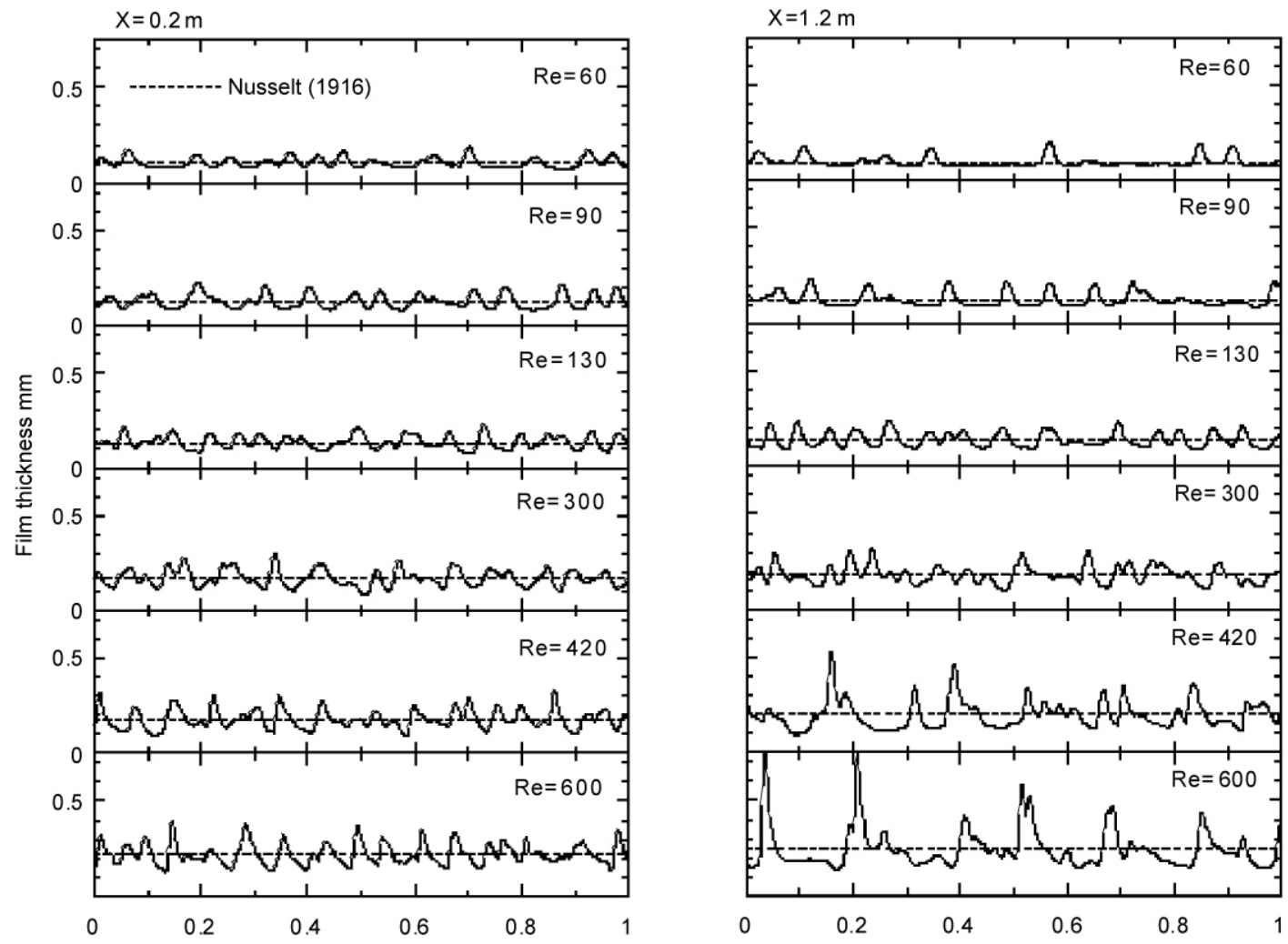

Fig. 6. Local film thickness $(\delta)$ measured at $0.2 \mathrm{~m}$ and $1.2 \mathrm{~m}$ from the inlet (adapted from Koizumi, Ohtake, and Ikeda [35]).

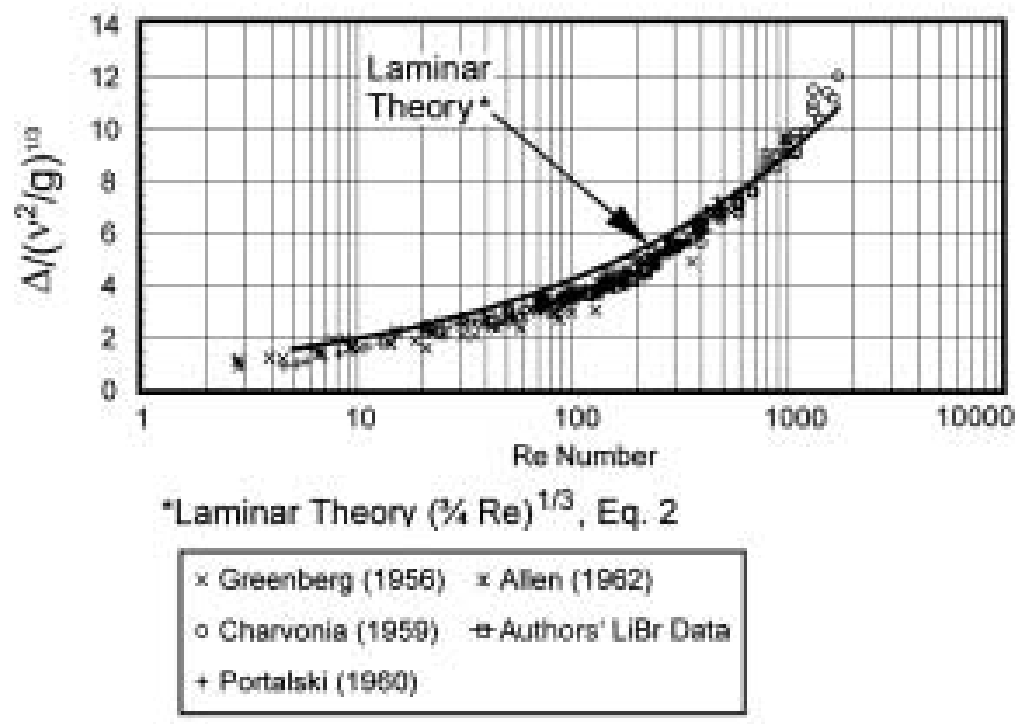

Fig. 7. Data on film thickness from hydrodynamic tests conducted with water, $55 \mathrm{wt} \% \mathrm{LiBr}$, glycerin, carbon tetrachloride, ethyl alcohol, and isopropyl alcohol. 
Unfortunately, heat and mass transfer equipment operate in this nebulous range of Re number flows; consequently, the use of the Nusselt film thickness may under predict the coupled heat and mass transfer problem. As the Re number further increases towards 1600 , turbulent flow occurs, and the data transitions back toward the Nusselt correlation.

Inspection of the data of Greenberg and Portalski shows a trending of the film thickness with the Ka number. As the Ka number increases, a monatomic decrease is observed in the film thickness. Greenberg had observed that increasing the surface tension also increased the wave amplitude. Interfacial tension induces a pressure difference in the liquid film as described by Young's equation. The thin film substrate has a lower surface tension than the adjacent roll wave because of the difference in curvature of the substrate and the roll wave. The surface tension gradient may strengthen the structure of the wave, causing the amplitude to increase as the wave picks up fluid from secondary flows that penetrate into the substrate.

According to Kapitza's theory, an increase in amplitude corresponds to a reduction in film thickness and in part explains the deviation between the measured data of Fig. 7 and Nusselt's laminar theory. By definition, an increase in surface tension results in an increase in Ka number. Therefore, the Re number and the Ka number were selected to correlate data within the ranges observed in our heat and mass transfer testing, which was independent of the hydrodynamic testing. For the heat and mass transfer testing, the Re number ranged from 100 to 400, while for 64 through 60 wt \% LiBr, the Ka number has a range of 400 through 850 , respectively. Our data on 55 wt \% $\mathrm{LiBr}$ observed on a $19.05-\mathrm{mm}$ pipe and Greenberg's data for glycerin and ethyl alcohol were used in the correlation. Portalski's [15] data were excluded because of the volume-averaged measurement technique used in his study; ${ }^{2}$ however, Portalski's data in the pertinent

\footnotetext{
${ }^{2}$ A volume-averaged film thickness is derived from the volume of a drained liquid and the wetted surface area; it represents the entire flow field.
}

$\mathrm{Re}$ and $\mathrm{Ka}$ number ranges are superimposed on the correlation, with the results plotted in Fig. 8. The water data of Allen [16] and Charvonia [14] were excluded, since they were outside the range of interest of our $\mathrm{Ka}$ values. The $\mathrm{Nt}$ correlation for the range of conditions typically observed in heat and mass transfer equipment therefore becomes

$$
\mathrm{Nt}=1.4\left\{\frac{\mathrm{Re}^{0.472}}{\mathrm{Ka}^{0.208}}\right\}
$$

The regression equation explains $95.7 \%$ of the total variation in the data about the average (i.e., an $\mathrm{R}^{2}$ of 0.957 ). The correlation predicts the regression data within an average absolute deviation of $\pm 4.0 \%$ (Fig. 8). Portalski’s data, although not used in the regression, are predicted within $10 \%$ and are slightly higher than the correlation because of his rudimentary technique of measuring the total volume flow and dividing by the wetted area.

According to Eq. 7, an increase in the Re number increases the film thickness, while an increase in the Ka number decreases the film thickness. This correlation is consistent with the data in Fig. 7 and with the observation made by Greenberg [13] concerning the effects of surface tension. Note that these films are very thin, about twice the thickness of a human hair, and any error in predicting the film's thickness will cause significant error in predicting heat and/or mass transfer processes. Because many studies have overlooked the subtle effect of the roll waves accelerating down an absorber, the film thickness has been overpredicted, as is evidenced by the numerous wavy-laminar flow studies that have used the Nusselt correlation.

Jayanti and Hewitt [36] observed that the heat transfer process in the wave was dominated by thermal conduction. They concluded that the effect of roll waves on heat transfer in thin films is not directly related to convection effects. Rather, its effect is indirect and due to the effective thinning of the film. Their observations agree with those of Clegg and Portalski [27], who had experimentally proven that roll

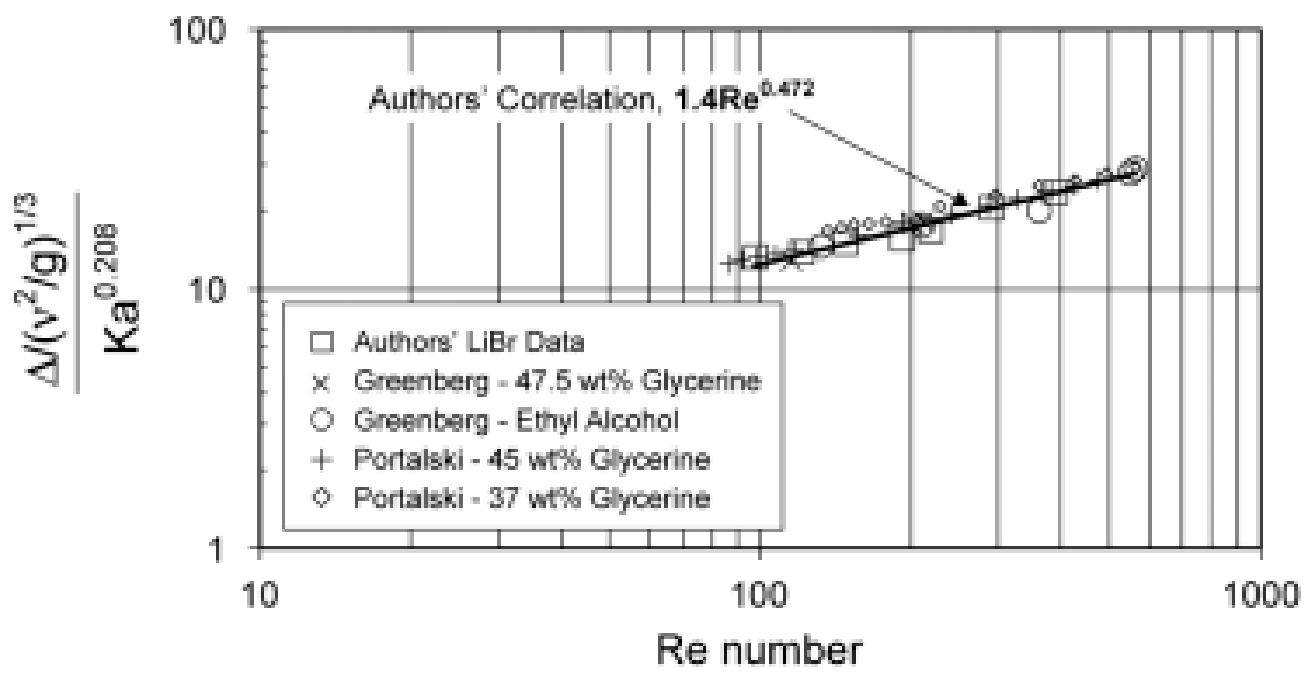

Fig. 8. The correlation predicts the regression data within an average absolute deviation of $\pm 4.0 \%$; Portalski's data is plotted but was not used in the regression analysis. 
waves thin the film in wavy flow. Blass [7] believed the heat transport resistance is located in the liquid layer close to the wall, which is approximately the thickness of the substrate film. Conlisk [37] also believed that the falling film is conduction-dominated. Using ananalytical closed-form solution, Conlisk developed a design procedure that assumes that the film is very thin and slowly varying in the direction of gravity. Conlisk showed the mass transfer is driven more by heat effects than by the mixing effects in the waves. His solution for heat and mass transfer predicted very well the data for outlet mass fraction and total mass absorbed published by Miller and Perez-Blanco [38].

Miller [34] also found the convection effects small and conduction more prominent within the Re number range of 100 to 400 . However, as the Re number exceeds 400 , Miller observed that the enhancement of mass transfer was caused more by convective motion than by conduction. The predominance of convection at higher Re numbers was proven by Wasden and Dukler [39], who conducted simulations at a Re number of 880 , and also by Patnaik and PerezBlanco [5,6], who studied falling film flows having a Re number of 400 .

Hence, an accurate measure of film thickness is of paramount importance for understanding the transport processes within falling film absorption incurring simultaneous heat and mass transfer. Equation 7 provides a simplistic correlation for accurately predicting the time-averaged film thickness in fully developed wavy-laminar flow with a Re number range of 100 through 400 and a Ka number range of 400 through 850 . The average absolute deviation between all the experimental regression data and the $\mathrm{Nt}$ corelation (Eq. 7) is less than $\pm 4.0 \%$.

\section{CONCLUSIONS}

Experimental results showed that the falling film enters as a smooth laminar flow. Within about $100 \mathrm{~mm}$ the falling film becomes unstable and transitions into small-amplitude wavy flow. The waves grow in length and amplitude and become roll waves. Fully developed flow requires large starting lengths, on the order of $1000 \Delta$, down the pipe; and the starting length increases as the flow increases.
Decreasing the pipe diameter causes the amplitude of the wavy flow to diminish; it also diminishes as the flow transitions into the laminarturbulent regime.

Video recordings of the falling film were made at 130-, 230-, and 400-mm stations along a $19.05-\mathrm{mm}$ OD test pipe. These results show a thinning of the film, due to physics, proposed by Dukler [28] and Brauner and Maron [1]. The roll waves accelerate down the pipe as they slide over a laminar substrate, and they grow in mass as they sweep up liquid from within the film's substrate. Subsequently, the average film thickness thins and can be $10-25 \%$ less than the value calculated by the equations formulated by Nusselt [30].

Hence, the Nt number for the reduced experimental data was less than that calculated by Nusselt's laminar theory as the Re number increased from 50 to 400 . Further increasing the Re number to 1600 causes the film to become fully turbulent, and the deviation between the experimental data and numbers derived from Nusselt's formulation diminishes. However, heat and mass transfer equipment operate in the nebulous wavy-laminar flow regimes. Therefore, use of Nusselt's theory can over predict the film thickness for wavy-laminar flow.

Increasing the Re number increases the film thickness because of the increase in mass flow rate per unit of wetted perimeter. Increasing the Ka number causes a decrease in the film thickness. Regression analysis showed that the Re and Ka numbers describe the data trends in wavy-laminar flow. The $\mathrm{Nt}$ correlation has an $\mathrm{R}^{2}$ of 0.957 and predicts the experimental data within an average absolute deviation of $\pm 4.0 \%$. Hence, for wavy-laminar flow in the Re number range of $50-400$, film thickness is a function of inertia, friction, and surface tension.

\section{ACKNOWLEDGMENTS}

Bill Ryan, formerly of the Gas Research Institute, sponsored the research reported herein under contract number 5089-243-1844. We also appreciate the help of Vikas Patnaik and Daoud Jandal in collecting and reducing the hydrodynamic data on falling films. Their individual efforts provided key information to substantiate the concepts of a conduction-dominated thinning film for wavy-laminar falling film flow. 


\section{NOMENCLATURE}

\section{SYMBOL DESCRIPTIVE}

A

$\mathrm{D}$

$\mathrm{D}_{\mathrm{h}}$

g

m

$\mathrm{P}$

$\overline{\mathrm{u}}$

X

y

$\Delta$

$\delta$

$\rho$

v

$\mu$

$\lambda$

$\tau$

$\sigma$

\section{Subscripts}

o

$\mathrm{pk}$

$\mathrm{s}$

wall
Cross-sectional area

Pipe diameter

Hydraulic diameter $\{4 \mathrm{~A} / \mathrm{P}\}$

Gravity

Mass flow rate

Wetted perimeter $\left\{\pi \mathrm{D}_{\mathrm{o}}\right\}$

Average falling film velocity

Coordinate in direction of flow

Coordinate normal to direction of flow

Time-averaged film thickness

Local time-dependent film thickness

Density

Kinematic viscosity

Dynamic viscosity

Wavelength of a roll wave

Shear stress

Surface tension

Outside

Peak

Substrate

Pipe wall

\section{Dimensionless Groups}

$\begin{array}{lll}\mathrm{Re} & \frac{\rho \overline{\mathrm{u}} \mathrm{D}_{\mathrm{h}}}{\mu}=\frac{4 \dot{\mathrm{m}}}{(\mathrm{P} \cdot \mu)} \\ \mathrm{Fr} & \text { Froude number } & \frac{\overline{\mathrm{u}}^{2}}{\mathrm{~g} \Delta} \equiv \frac{\mathrm{Re}^{2}}{16 \cdot(\mathrm{Nt})^{3}} \\ \mathrm{Ka} & \frac{\sigma}{\rho\left(v^{4} \mathrm{~g}\right)^{1 / 3}} \\ \mathrm{Nt} & \text { Kapitza number } & \left(\frac{\Delta}{\left(v^{2} / \mathrm{g}\right)^{1 / 3}}\right. \\ \mathrm{He} & \text { Normalized film thickness } & \frac{\rho \overline{\mathrm{u}}^{2} \Delta}{\sigma} \equiv \frac{\mathrm{Re}^{2}}{16 \cdot \mathrm{Ka} \cdot \mathrm{Nt}}\end{array}$




\section{REFERENCES}

[1] Brauner, N., and Maron, D. M. 1983. "Modeling of Wavy Flow in Inclined Thin Films." Chem. Eng. Sci. 38, no. 5: 775-88.

[2] Wasden, F. K., and Dukler, A. E. 1989. "Insights into the Hydrodynamics of Free-Falling Wavy Films." AIChE J. 35, no. 2: 187-95.

[3] Morioka, I., and Kiyota, M. 1991. "Absorption of Water Vapor into a Wavy Film of an Aqueous Solution of LiBr." JSME Int. $J$., Series II, 34, no. 2: 183-88.

[4] Yang, R., and Jou, D. 1993. "Heat and Mass Transfer on the Wavy Film Absorption Process." Can. J. Chem. Eng. 71:53338.

[5] Patnaik, V. 1994. "Combined Heat and Mass Transfer in WavyFilm Absorption." Ph.D. diss., Pennsylvania State Univ., University Park, Penn.

[6] Patnaik, V., and Perez-Blanco, H. 1996. "A Study of Absorption Enhancement by Wavy Film Flows." Int. J. Heat and Fluid Flow 17:71-77.

[7] Blass, E. 1977. "Gas-Film Flow in Tubes." Chem.-Ing.-Tech. (in German) 49:95-105.

[8] Wekken, B. J. C. van der, and Wassenaar, R. H. 1988. "Simultaneous Heat and Mass Transfer Accompanying Absorption in Laminar Flow over a Cooled Wall." Int. J. Refrig. 11, no. 2: 70-77.

[9] Habib, H. M., and Wood, B. D. 1990. "Simultaneous Heat and Mass Transfer for a Falling Film Absorber-The Two-Phase Flow Problem." In Solar Engineering, Proc. 12th Annual ASME Int. Solar Energy Conf., ASME, New York, pp. 61-67.

[10] Yang, R., and Wood, B. D. 1992. "A Numerical Modeling of an Absorption Process on a Liquid Falling Film." Solar Energy 48, no. 3: 195-98.

[11] Miller, W. A.; Perez-Blanco, H.; and Patnaik, V. 1992. Advanced Surfaces for Vertical Tube Absorbers. GRI-93/0061. Gas Research Institute, Chicago, September.

[12] Morioka, I.; Kiyota, M.; and Nakao, R. 1993. "Absorption of Water Vapor into a Film of Aqueous Solution of LiBr Falling along a Vertical Pipe.” JSME Int. J., Series B, 36, no. 2: 351-56.

[13] Greenberg, A. B. 1956. "The Mechanics of Film Flow on a Vertical Surface.” Ph.D. diss., Purdue Univ., Lafayette, Ind.

[14] Charvonia, D. A. 1959. "A Study of the Mean Thickness of the Liquid Film and the Characteristics of the Interfacial Surface in Annular, Two-Phase Flow in a Vertical Tube, Including a Review of the Literature.” Ph.D. diss., Purdue Univ., Lafayette, Ind.

[15] Portalski, S. 1960. "The Mechanism of Flow in Wetted Wall Columns." Ph.D. diss., Univ. of London, London, England.

[16] Allen, J. M. 1962. "Some Studies of Falling Liquid Films." Ph.D. diss., Victoria Univ. of Manchester, England.

[17] Clegg, A. J. 1969. "Studies of Film Flow on Wetted Wall Columns." Ph.D. diss., Univ. of Surrey, Guildford, Surrey, England.

[18] Chu, K. J., and Dukler, A. E. 1974. "Statistical Characteristics of Thin Wavy Films, Part II: Studies of the Substrate and Its Wave Structure" AIChE J. 20, no. 4: 695-706.

[19] Solorio, F. J., and Sen, M. 1987. "Linear Stability of a Cylindrical Falling Film.” J. Fluid Mech. 183:365-77.
[20] Benjamin, T. B. 1957. "Wave Formation in Laminar Flow Down an Inclined Plane." J. Fluid Mech. 2:554-74.

[21] Brauer, G. H. 1956. "Strömung und Wärmeübergang bei Rieselfilmen." VDI (Ver. Deut. Ingr.)—Forschungsheft 457, VDI-Verlag GMBH, Düsseldorf, Germany.

[22] Grimley, S. S. 1945. "Liquid Flow Conditions in Packed Towers." Trans. Inst. Chem. Eng. 23:228-35.

[23] Kapitza, P. L. 1948. "Wave Flow of Thin Films of Viscous Liquids" (in Russian). Zh. Eksp. Teor. Fiz. 18:3-28.

[24] Ishigai, S.; Nakanisi, S.; Koizumi, T.; and Oyabi, Z. 1972. "Hydrodynamics and Heat Transfer of Vertical Falling Films." Bull. JSME 15, no. 83: 594-602.

[25] Fulford, G. D. 1964. "The Flow of Liquids in Thin Films." $A d v$. Chem. Eng. 5:151-236.

[26] Brauner, N. 1989. "Modelling of Wavy Flow in Turbulent FreeFalling Films.” Int. J. Multiphase Flow 15, no. 4: 505-20.

[27] Clegg, A. J., and Portalski, S. 1972. "An Experimental Study of Wave Inception on Falling Liquid Films." Chem. Eng. Sci. 27:1257-65.

[28] Dukler, A. E. 1976. "The Role of Waves in Two-Phase Flow: Some New Understandings" (Award Lecture). Chem. Eng. Educ. 10:108-38.

[29] Brauner, N., and Maron, D. M. 1982. "Characteristics of Inclined Thin Films, Waviness and the Associated Mass Transfer." Int. J. Heat Mass Transfer 25, no. 1: 99-109.

[30] Nusselt, W. 1916. "Die Oberflächenkondensation des Wasserdampfes" (in German). Zeitschrift VDI 60:541-46.

[31] Hopf, L. 1910. "Turbulenz bei einem Flusse." Ann. Physik. 32:777-808.

[32] Dukler, A. E. 1959. "Dynamics of Vertical Falling Film Systems." Chem. Eng. Prog. 55, no. 10: 62-67.

[33] Kapitza, P. L., and Kapitza, S. P. 1949. "Wave Flow of Thin Layer of Viscous Fluid" (in Russian). Zh. Eksp. Teor. Fiz. 19:105-20.

[34] Miller, W. A. 1998. "The Experimental Analysis of Aqueous Lithium Bromide Vertical Falling Film Absorption.” Ph.D. diss., Univ. of Tennessee, Knoxville, Tenn.

[35] Koizumi, Y., Ohtake, H. and Ikeda, S. 2000. "Characteristics of Falling Liquid Film on the Outer Surface of a Vertical Pipe (Minimum Wetting Rates and Waves on the Film)." ASME Poster Session, ASME International Congress, Orlando, Fla., November.

[36] Jayanti, S., and Hewitt, G. F. 1997. "Hydrodynamics and Heat Transfer of Wavy Thin Film Flow." Int. J. Heat Mass Transfer 40, no. 1: 179-90.

[37] Conlisk, A. T. 1995. "Analytical Solutions for the Heat and Mass Transfer in a Falling Film Absorber." Chem. Eng. Sci. 50, no. 4: 651-60.

[38] Miller, W. A., and Perez-Blanco, H. 1994. "Vertical-Tube Aqueous LiBr Falling Film Absorption Using Advanced Surfaces." In Proceedings of the International Absorption Heat Pump Conference, AES-Vol. 31, ed. R. Radermacher et al., ASME, New York.

[39] Wasden, F. K., and Dukler, A. E. 1990. "A Numerical Study of Mass Transfer in Free-Falling Wavy Films.” AIChE J. 36, no. 9: 1379-90. 